\title{
Comparación de desinfección de diferentes marcas de punta de gutapercha con hipoclorito de sodio.
}

\author{
Comparison of disinfection of different brands \\ of gutta-percha tip with sodium hypochlorite.
}

\author{
Jorge Morales García,** Mónica Badillo Barba,* María Guadalupe Chávez García, ${ }^{\S}$ \\ Vanessa García Ruíz, ${ }^{\S}$ Adolfo Gutiérrez García ${ }^{\S}$
}

RESUMEN

En la terapia endodóncica uno de los principales objetivos es eliminar y prevenir la infección o reinfección del sistema de conductos radiculares y/o los tejidos perirradiculares. Los materiales de obturación utilizados podrían introducir microorganismos a este sistema previamente desinfectado e impedir el éxito del tratamiento. Diversos estudios han demostrado que los conos de gutapercha pueden estar contaminados al ser tomados directamente del empaque, aún sellado y recién abierto. Objetivo: Comparación del grado de desinfección de tres marcas diferentes de puntas de gutapercha. Material y métodos: Es un estudio experimental, comparativo, observacional y de corte transversal. En el cual se analizarán tres marcas diferentes de gutaperchas \#35 (Maillefer, Hygienic y Meta-Biomed) para saber qué desinfección hay con el hipoclorito de sodio $(\mathrm{NaOCl})$ al $5.25 \%$. Se llevó a cabo el análisis descriptivo para determinar medidas de tendencia central y medidas de dispersión mediante la prueba estadística de ANOVA $\mathrm{p} \leq 0.05$. Conclusión: De acuerdo con los resultados de nuestro estudio no se encontró diferencia significativa sobre la marca de gutapercha y el grado de descontaminación después de un minuto de ser sumergidas en hipoclorito de sodio al 5.25\%.

Palabras clave: Gutaperchas, hipoclorito de sodio, microorganismos, desinfección.

\section{INTRODUCCIÓN}

L os microorganismos y sus productos son el principal factor etiológico de las patologías pulpares y

\footnotetext{
* Profesor Investigador, Departamento Atención a la Salud.

* Profesor invitado de la UNITEC y UIC.

$\S$ Alumno.
}

Universidad Autónoma Metropolitana-Xochimilco. Ciudad de México, México.

Recibido: 31 Mayo 2019.

Aceptado para publicación: 11 Febrero 2020.

\section{ABSTRACT}

In endodontic therapy one of the main objectives is to eliminate and prevent infection or reinfection of the root canal system and/or periradicular tissues. The sealing materials used could introduce microorganisms to this previously disinfected system and impede the success of the treatment. Several studies have shown that gutta-percha cones can be contaminated by being taken directly from the package, still sealed and newly opened. Objective: Comparison of the degree of disinfection of 3 different brands of gutta-percha points. Material and methods: It is an experimental, comparative, observational and cross-sectional study. Where 3 different brands of gutta percha \# 35 (Maillefer, Hygienic and Meta-Biomed) will be analyzed to know what disinfection there is with sodium hypochlorite ( $\mathrm{NaOCl}$ ) at $5.25 \%$. The descriptive analysis was carried out to determine measures of central tendency and measures of dispersion through the statistical test of ANOVA $p \leq 0.05$. Conclusion: According to the results of our study there is no significant difference on the gutta-percha brand and its decontamination at the moment of being submerged in $5.25 \%$ sodium hypochlorite.

Keywords: Guttaperchas, sodium hypochlorite, microorganisms, disinfection. periapicales, y desempeñan un papel importante en la inducción y progresión de estas condiciones. ${ }^{1,2}$ Por lo tanto, en la práctica endodóncica, la eliminación o la reducción significativa de estos microorganismos del canal radicular por medios químicos y mecánicos es una de las características cruciales para un tratamiento exitoso. ${ }^{3} \mathrm{Se}$ debe tener cuidado durante este procedimiento, debido a que la contaminación de los materiales de relleno podría perpetuar la lesión debido a su contaminación. ${ }^{4}$

En la actualidad, la gutapercha es el material de relleno para el conducto radicular más utilizado. Son biocompatibles, dimensionalmente estables, radiopacos y termoplásticos; presenta propiedades 

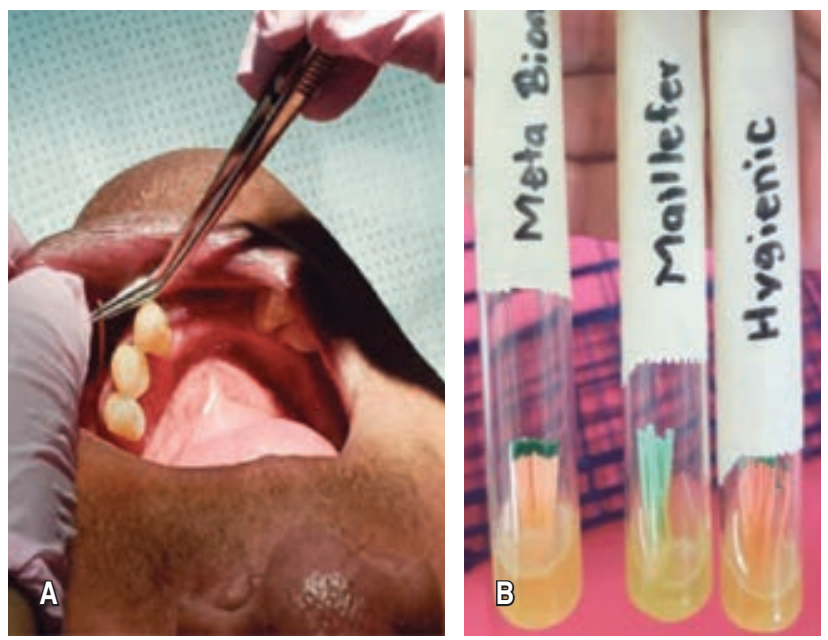

Figura 1: A) Contaminación de gutaperchas. B) Tubos de caldo nutritivo.

antimicrobianas debido a su alto contenido de óxido de zinc (59-76\%). ${ }^{5,6}$ Sin embargo, la gutapercha no es un material resistente a los procesos de esterilización convencionales en calor húmedo o seco. Aunque se comercializan en envases sellados, no son estériles. Por lo tanto, para mantener la cadena aséptica, los conos de gutapercha requieren una descontaminación rápida en el sillón antes de su uso. ${ }^{7}$

La literatura registra varios métodos químicos para la descontaminación de los conos de gutapercha en odontología. ${ }^{8-13}$ Entre los que se incluyen: polivinilpirrolidona yodo, glutaraldehído, hipoclorito sodio, peróxido de hidrógeno, clorhexidina al 2\%, formaldehído, ácido peracético y yodo-alcohol. ${ }^{4}$ De ellos el hipoclorito de sodio $(\mathrm{NaOCl})$ es la sustancia más utilizada para la desinfección debido a la actividad bactericida y esporicida rápida sobre la gutapercha. ${ }^{14} \mathrm{El}$ método recomendado consiste en tratar los conos usando hipoclorito de sodio (5.25\%) durante un minuto. La solución de Milton (1\%) y Dakin $(0.5 \%)$ también han sido utilizadas con un tiempo de sumersión mayor que va desde los tres a los 25 minutos. ${ }^{15,16}$

Varios estudios indican el tiempo requerido para la desinfección química de conos de acuerdo con la concentración de hipoclorito de sodio; no obstante, existe poca información sobre cuánto tiempo se pueden sumergir los conos sin sufrir cambios morfológicos, como podría ser la disminución del cono por contracción, el aumento de la elasticidad, el cambio en la textura de la superficie y las propiedades físicas de los conos, además de la formación de cristales. Tampoco existe algún estudio que nos indi- que si hay diferencia significativa sobre la desinfección de diferentes marcas de gutapercha. ${ }^{14}$

\section{Objetivo}

Comparar el grado de desinfección de tres marcas diferentes de puntas de gutapercha.

\section{MATERIAL Y MÉTODOS}

Es un estudio experimental, comparativo, observacional y de corte transversal. En el cual se analizarán tres marcas diferentes de gutaperchas \#35 (Maillefer, Hygienic y Meta-Biomed) para saber en cuál de ellas se logra una desinfección mayor al ser sumergidas en hipoclorito de sodio al $5.25 \%$ marca «Cloralex» durante un minuto. Previo al estudio se efectuó una estandarización obteniendo una kappa de 0.82. La base de datos se realizó en el programa SPSS versión 24, con lo que se llevó a cabo el análisis descriptivo para determinar medidas de tendencia central y de dispersión mediante la prueba estadística de ANOVA $p \leq 0.05$.

\section{Procedimiento}

El estudio se realizó en cuatro fases:

\section{Contaminación de gutaperchas}

En esta primera fase se pidió autorización a un paciente
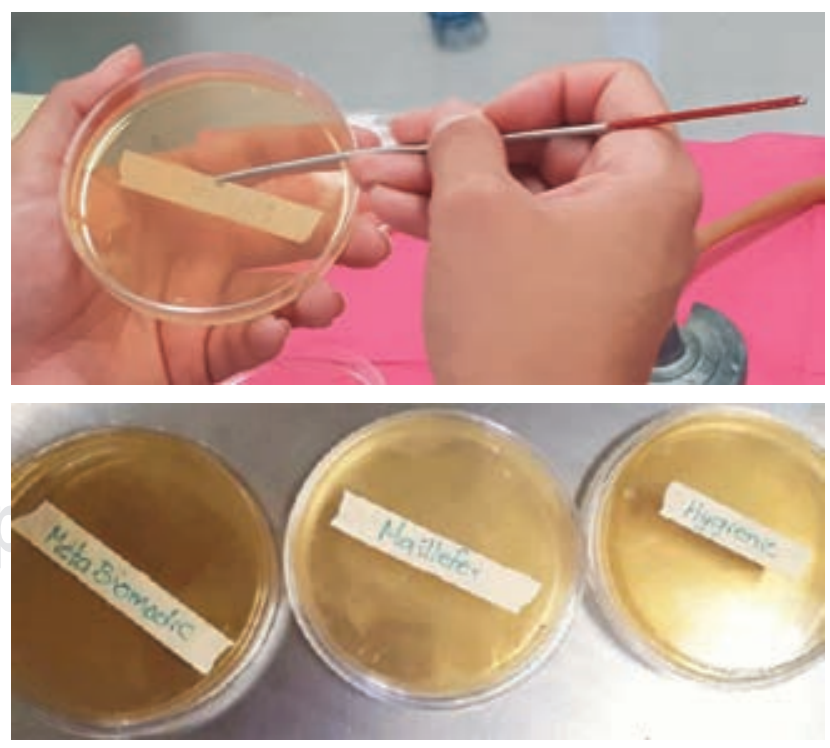

Figura 2: Cultivo bacteriológico en cajas de Petri. 

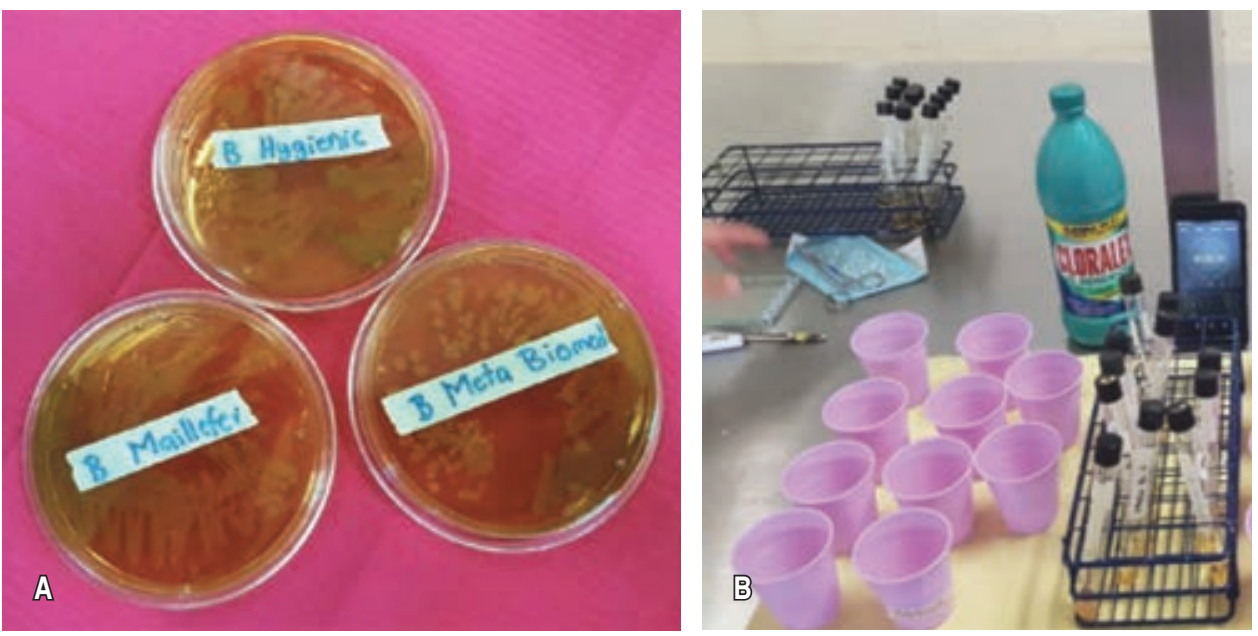

Figura 3:

A) Muestras controles contaminadas.

B) Proceso de desinfección.

con enfermedad periodontal severa que decidió participar en el estudio, se le informó al paciente del riesgo mínimo y se le dio a firmar el consentimiento informado. Se procedió a pasar sobre áreas con presencia de biofilm cada una de las puntas de gutapercha que fueron utilizadas en el estudio (Figura 1A).

Una vez contaminadas fueron introducidas en tubos que contenían cultivo caldo nutritivo, previamente codificados. Dichas muestras se almacenaron a una temperatura de $37{ }^{\circ} \mathrm{C}$ por un periodo de 24 horas (Figura 1B).

\section{Cultivo bacteriológico en el agar infusión cerebro} corazón de muestras controles

Se realizó el cultivo por medio de un estriado simple en el agar infusión cerebro corazón contenido en las cajas de Petri, previamente codificadas; se tomó una muestra control de cada marca de gutapercha de los tubos de caldo nutritivo. Las cajas se almacenaron a una temperatura de $37^{\circ} \mathrm{C}$ por un periodo de 24 horas. Esto para corroborar la contaminación de las gutaperchas (Figura 2).

\section{Desinfección y aislamiento bacteriológico}

Una vez corroborado la presencia de unidades formadoras de crecimiento (UFC) de las gutaperchas mediante las muestras controles, se procedió a la desinfección por medio de hipoclorito (Figura 3A). Se colocó cada punta de gutapercha en un vaso con $5 \mathrm{~mL}$ de hipoclorito de sodio marca «Cloralex» al $5.25 \%$ durante un minuto, se secaron con gasas estériles y se colocaron en tubos que contienen caldo nutritivo, previamente codificados. Dichas muestras se almacenaron a una temperatura de $37^{\circ} \mathrm{C}$ por un periodo de 24 horas (Figura 3B).
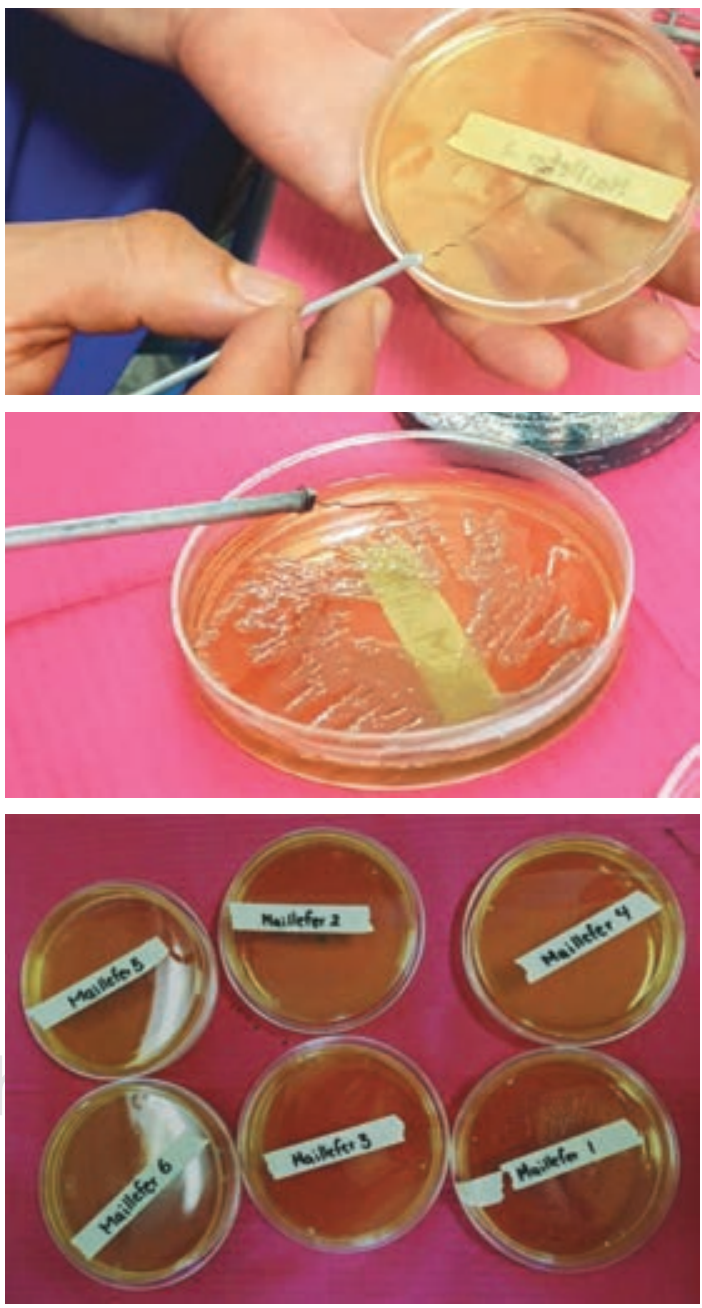

Figura 4: Estriado simple en cajas de agar infusión cerebro corazón. 
Tabla 1: Análisis descriptivo unidireccional.

\begin{tabular}{|c|c|c|c|c|c|c|c|}
\hline & \multirow[b]{2}{*}{$\mathrm{n}$} & \multirow[b]{2}{*}{ Media \pm DE } & \multirow[b]{2}{*}{ Error estándar } & \multicolumn{2}{|c|}{$\begin{array}{l}\text { 95\% del intervalo de confianza } \\
\text { para la media }\end{array}$} & \multirow[b]{2}{*}{ Mínimo } & \multirow[b]{2}{*}{ Máximo } \\
\hline & & & & Límite inferior & Límite superior & & \\
\hline Meta-Biomedic & 10 & $1.8000 \pm 0.42164$ & 0.13333 & 1.4984 & 2.1016 & 1.00 & 2.00 \\
\hline Maillefer & 10 & $1.8000 \pm 0.42164$ & 0.13333 & 1.4984 & 2.1016 & 1.00 & 2.00 \\
\hline Hygienic & 10 & $1.9000 \pm 0.31623$ & 0.10000 & 1.6738 & 2.1262 & 1.00 & 2.00 \\
\hline Total & 30 & $1.8333 \pm 0.37905$ & 0.06920 & 1.6918 & 1.9749 & 1.00 & 2.00 \\
\hline
\end{tabular}

\section{Cultivo bacteriológico después de la inmersión}

Se realizó el cultivo por medio de un estriado simple en el agar infusión cerebro corazón contenido en las cajas de Petri, previamente codificadas; las muestras fueron obtenidas de los tubos de caldo nutritivo. Las cajas se almacenaron a una temperatura de $37^{\circ} \mathrm{C}$ por un periodo de 24 horas (Figura 4).

\section{RESULTADOS}

En la Tabla 1 podemos observar mediante el análisis descriptivo unidireccional y en la Figura 5 barras de error simple con un intervalo de confianza del 95\%, el promedio de la media en el crecimiento bacteriano fue de 1.83 $(\mathrm{DE} \pm 0.37)$. La marca Meta-Biomedic y Maillefer una media de 1.80 ( $D E \pm 0.42$ ), respectivamente, y la marca Hygienic con 1.90 (DE \pm 0.31 ).

La Figura 6 y la Tabla 2, indican que $16.7 \%$ de todas las muestras presentaron UFC. Sin embargo, sólo $20 \%$ de las muestras desinfectadas de la marca Meta-Biomedic y Maillefer presentaron UFC, respectivamente. La marca Hygienic es la que presentó menor UFC en sus muestras con $10 \%$.

La Tabla 3, en la prueba de ANOVA revela $p=$ 0.804 , por lo que no existen diferencias significativas en la descontaminación bacteriana por marca de los conos de gutapercha después de haber sido sumergidas en el hipoclorito por el periodo de tiempo.

\section{DISCUSIÓN}

La gutapercha no puede ser esterilizada por métodos convencionales debido a su termoplasticidad. El NaOCl se ha usado ampliamente como un irrigante endodóncico y tiene una acción esterilizante en conos contaminados artificialmente. Muchos investigadores han encontrado que es eficaz para desinfectar los conos de gutapercha en diferentes concentraciones. ${ }^{17}$

Montgomery ${ }^{18}$ y Kayaoglu y colegas $^{5}$ demostraron que los conos comercialmente disponibles, tomados directamente del paquete sellado del fabricante, albergan microorganismos cultivables. Mientras que el número de estos microorganismos era bastante bajo al momento de abrir el paquete, el uso clínico de los paquetes aumentó el número de microorganismos que contaminan los conos de gutapercha.

La selección del agente químico para la descontaminación de conos de gutapercha y el tiempo utilizado en el presente estudio se basó en datos de la literatura como lo reportado por Gomes BP, y Nurban O, quienes demostraron que el $\mathrm{NaOCl}$ en una concentración de 5.25\% eliminó las esporas de la gutapercha después de un minuto de contacto. 6,19

En el año 2013 Pradeep Ky colaboradores compararon la eficacia de cinco agentes desinfectantes, concluyendo que el hipoclorito de sodio (5\%) y una combinación de

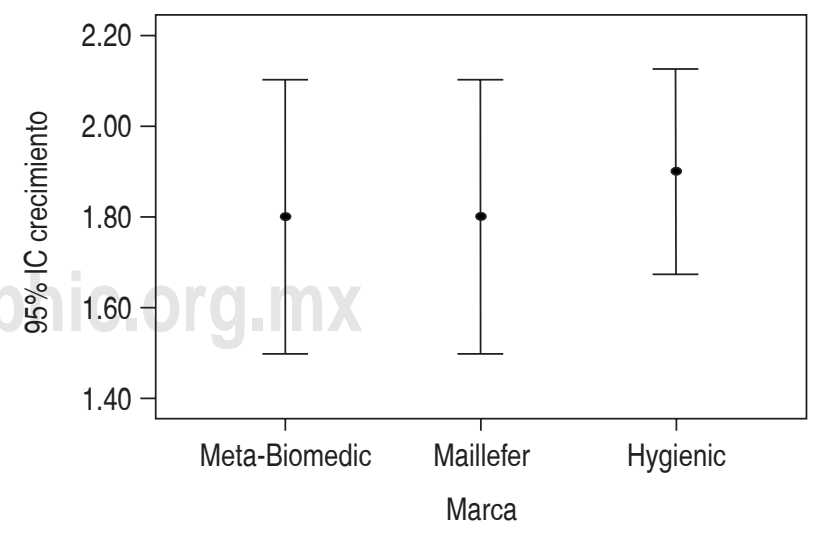

Figura 5: Barra de error simple. 


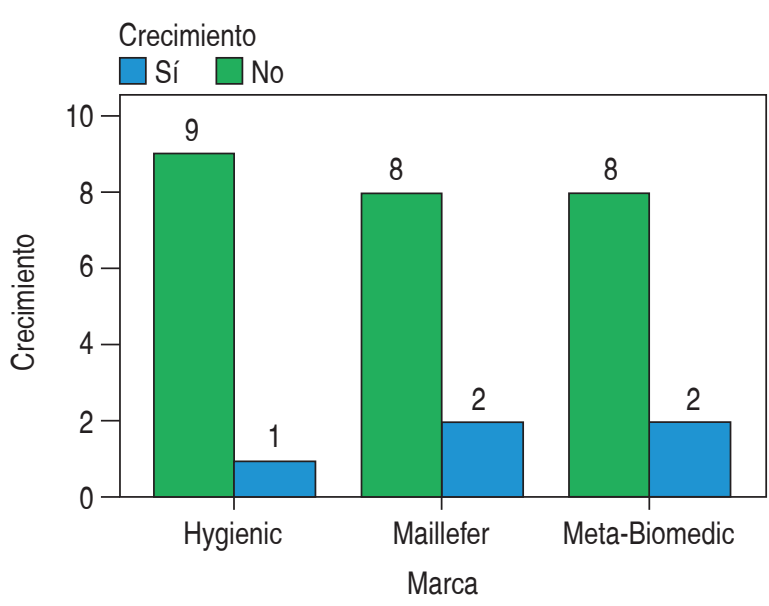

Figura 6: Crecimiento bacteriano por marca.

Tabla 2: Análisis descriptivo de UFC por marca.

\begin{tabular}{lcrrr} 
& & \multicolumn{2}{c}{ Crecimiento } & \\
\cline { 3 - 4 } & & Sí & No & Total \\
\cline { 3 - 4 } & & & \\
\hline \multirow{2}{*}{ Meta-Biomedic } & Recuento & 2.0 & 8.0 & 10 \\
& $\%$ & 20.0 & 80.0 & 100.0 \\
Maillefer & Recuento & 2.0 & 8.0 & 10 \\
& $\%$ & 20.0 & 80.0 & 100.0 \\
Hygienic & Recuento & 1.0 & 9.0 & 10 \\
& $\%$ & 10.0 & 90.0 & 100.0 \\
Total & Recuento & 5.0 & 25.0 & 30 \\
& $\%$ & 16.7 & 83.3 & 100.0 \\
\hline
\end{tabular}

clorhexidina (1.5\%) y cetrimida (15\%) son los desinfectantes químicos más efectivos en la esterilización de gutapercha. ${ }^{20}$ Por su parte, Raveendran L y su equipo reportaron que la inmersión de los conos GP en una solución de CHX al $2 \%$ y $\mathrm{NaOCl}$ al $3 \%$ durante un minuto es un método eficaz para promover su desinfección. ${ }^{15}$

Candeiro y su grupo mencionaron en su estudio que independientemente del tiempo de exposición, el 1\% de $\mathrm{NaOCl}$ y el $2.5 \%$ de $\mathrm{NaOCl}$ fueron los agentes más efectivos para la desinfección rápida de los conos de gutapercha. $^{21}$

Chandrappa MM y colaboradores, encontraron que el recuento bacteriano medio de $E$. faecalis o $S$. aureus fue menor después de tratar los conos con MTAD, el cual es una mezcla de doxiciclina, ácido cítrico introducido por Torabinejad en comparación con otras soluciones desin- fectantes para todos los intervalos de tiempo analizados. $\mathrm{El} \mathrm{NaOCl}$ en una concentración de $5.25 \%$ es la segunda solución desinfectante más efectiva, mientras que la clorhexidina al $2 \%$ fue la menos efectiva. ${ }^{22,23}$

Jiménez K y su grupo, en su estudio compararon dos concentraciones de hipoclorito de sodio ( $\mathrm{NaOCl}$ al 3.7\% y $\mathrm{NaOCl}$ al 5.8\%), para la desinfección de los conos de gutapercha. Los resultados no mostraron diferencias estadísticamente significativas en el conteo de UFC bacterianas entre sí. Tampoco se observaron diferencias significativas entre los grupos desinfectados durante uno o tres minutos. Concluyendo que todos los protocolos de $\mathrm{NaOCl}$ resultaron ser efectivos en la desinfección de los conos de gutapercha. ${ }^{1}$

Cardoso C y colegas, compararon la eficacia de diferentes agentes químicos en la contaminación de conos de gutapercha; encontrando que la clorhexidina, el hipoclorito de sodio, la polivinilpirrolidona yodada, el peróxido de hidrógeno y el glutaraldehído fueron los productos más efectivos. ${ }^{4}$

\section{CONCLUSIONES}

Del presente estudio se puede concluir que la efectividad del hipoclorito de sodio a una concentración del $5.25 \%$, con un tiempo de exposición de un minuto, ha resultado un agente químico desinfectante muy efectivo para descontaminar las puntas de gutapercha; gracias a ello, se pudo observar que en dicho estudio disminuyó la cantidad de microorganismos presentes en la gutapercha, siendo la marca Hygienic la que sobresalió de las otras dos marcas comerciales, con un mayor grado de desinfección, dando a nuestra hipótesis como nula, ya que nosotros pensábamos que la marca Maillefer, por el tipo de empaque que tenía, iba a resultar más estéril.

Además, reiteramos que el conocimiento sobre la desinfección previa de los conos de gutapercha antes de

\section{Tabla 3: Análisis ANOVA p $<0.05$.}

\begin{tabular}{lcrccc} 
& $\begin{array}{c}\text { Suma de } \\
\text { cuadrados }\end{array}$ & gl & $\begin{array}{c}\text { Media } \\
\text { cuadrática }\end{array}$ & F & Sig. \\
\hline $\begin{array}{l}\text { Entre grupos } \\
\begin{array}{l}\text { Dentro de } \\
\text { grupos }\end{array}\end{array}$ & 0.067 & 2 & 0.033 & 0.220 & 0.804 \\
Total & 4.100 & 27 & 0.152 & & \\
& 4.167 & 29 & & & \\
\hline
\end{tabular}


obturar los conductos radiculares ayudará a prevenir la persistencia de bacterias Gram negativas.

\section{BIBLIOGRAFÍA}

1. Jiménez K, Montero M, Cortés C, Rojas N, Zeledón R. Eficiencia de diferentes protocolos de desinfección de conos de gutapercha con NAOCL, ante las especies $S$. aureus y $E$. faecalis. Rev Cient Odontol. 2014; 10 (1): 37-41.

2. Panuganti V, Vivek VJ, Jayashankara CM, Anilkumar S, Girish SA, Nanjundasetty JK. Guttapercha disinfection: a knowledge, attitude, and practice study among endodontic postgraduate students in India. Saudi Endod J. 2016; 6: 127-130.

3. Manica SMH, Sallenave FR, Demarchi A, Farina AP, CecchinD, Albino SM. Effectiveness of different auxiliary chemical substances in the rapid disinfection of guttapercha points - an in vitro study. RFO Passo Fundo. 2015; 20 (1): 64-68.

4. Cardoso CL, Redmerski R, de Lucas Rodrigues BN, Regiane KC. Effectiveness of different chemical agents in rapid decontamination of gutta-percha cones. Braz J Microbiol. $2000 ; 31$ (1): 67-71.

5. Kayaoglu G, Gürel M, Ömürlü H, Bek ZG, Sadik B. Examination of guttapercha cones for microbial contamination during chemical use. J Appl Oral Sci. 2009; 17 (3): 244-247.

6. Gomes BP, Vianna ME, Matsumoto CU et al. Disinfection of guttapercha cones with chlorhexidine and sodium hypochlorite. Oral Surg Oral Med Oral Pathol Oral Radiol Endod. 2005; 100 (4): 512-517.

7. Taha MY, Al-Sabawi NA, Shehab EY. Rapid decontamination of guttapercha cones using different chemical agents. Al-Rafidain Dent J. 2010; 10 (1): 30-37.

8. Prado M, de Assis DF, Gomes BP, Simao RA. Effect of disinfectant solutions on the surface free energy and wettability of filling material. J Endod. 2011; 37 (7): 980-982.

9. Short RD, Dorn SO, Kuttler S. The crystallization of sodium hypochlorite on gutta-percha cones after the rapid-sterilization technique: an SEM study. J Endod. 2003; 29 (10): 670-673.

10. Pang NS, Jung IY, Bae KS, Baek SH, Lee WC, Kum KY. Effects of shortterm chemical disinfection of gutta-percha cones: Identification of affected microbes and alterations in surface texture and physical properties. J Endod. 2007; 33 (5): 594-598.

11. Giardino L, Savoldi E, Ambu E, Rimondini R, Palezona A, Debbia EA. Antimicrobial effect of MTAD, Tetraclean, Cloreximid, and sodium hypochlorite on three common endodontic pathogens. Indian J Dent Res. 2009; 20 (3): 391.

12. Demiryurek EO, Onuk EE, Yüksel G, Ciftci A. Evaluation of microbial contamination of resilon and gutta-percha cones and their antimicrobial activities. Afr J Microbiol Res. 2012; 6: 6275-6280.
13. Prado M, Gusman H, Gomes BP, Simao RA. The importance of final rinse after disinfection of gutta-percha and Resilon cone. Oral Surg Oral Med Oral Pathol Oral Radiol Endod. 2011; 111: 21-24.

14. Brito SMSM, Andrade VR, Gonccalves OSH. Guttapercha points surface alterations after sodium hypochlorite disinfection. Braz Dent Sci. 2013; 16 (3): 47-55.

15. Raveendran L, Mathew M, Pathrose S, Kottoor J, Mathew J. Chair side disinfection of guttapercha points - an in vitro comparative study between a herbal alternative propolis extract with $3 \%$ sodium hypochlorite, $2 \%$ chlorhexidine and $10 \%$ povidone iodine. Int J Bioassays. 2015; 4.10: 4414-4417.

16. Makade C, Shenoi PR, Morey E, Paralikar AV. Evaluation of antimicrobial activity and efficacy of herbal oils and extracts in disinfection of guttapercha cones before obturation. Restor Dent Endod. 2017; 42 (4): 264-272.

17. Yadav K, de Ataide ID, Ganoo A, Fernandes M, Lambor R. Evaluation of disinfection of gutta-percha cones and their surface changes using different chemical solutions. J Res Dent. 2016; 4: 76-80.

18. Montgomery S. Chemical decontamination of guttapercha cones with polyvinylpyrrolidone dine. Oral Surg. 1971; 31: 258-266.

19. Nurban O, Zeynep O, Berrin O. The rapid sterilization of guttapercha cones with sodium hypochlorite and glutaraldehyde. J Endod. 2006; 32: 1202-1204.

20. Pradeep K, Kidiyoor KH, Jain P, Rao N. Chair side disinfection of guttapercha points - An in vitro comparative study between 5 different agents at different concentrations. Endodontology. 2013; 25: 73.

21. Candeiro GTM, Akisue E, Campelo CF, Dos Santos SE, Do Vale MS, Iglecias EF et al. Analysis of demineralized chemical substances for disinfecting guttapercha cones. Iran Endod J. 2018; 13 (3): 318-322.

22. Chandrappa MM, Mundathodu N, Srinivasan R, Nasreen F, Kavitha $P$, Shetty A. Disinfection of gutta-percha cones using three reagents and their residual effects. J Conserv Dent. 2014; 17 (6): 571-574.

23. Da Motta PG, de Figueiredo CB, Maltos SM, Nicoli JR, Ribeiro Sobrinho AP, Maltos KL et al. Efficacy of chemical sterilization and storage conditions of gutta-percha cones. Int Endod J. 2001; 34: 435-439.

\section{Correspondencia:}

\section{Mónica Badillo Barba}

Paseo de las Galias Núm. 268,

Col. Lomas Estrella, Iztapalapa,

Ciudad de México, México.

E-mail: babm_1985@hotmail.com 